\title{
Central Respiratory Drive in Patients With Neuromuscular Diseases
}

\author{
Gemma Rialp MD PhD, Joan Maria Raurich MD PhD, Juan Antonio Llompart-Pou MD PhD, \\ Ignacio Ayestarán MD, and Jordi Ibáñez MD PhD
}

\begin{abstract}
BACKGROUND: The contribution of the central respiratory drive in the hypercapnic respiratory failure of neuromuscular diseases (NMD) is controversial. OBJECTIVE: To compare the $\mathrm{CO}_{2}$ response and the duration of weaning of mechanical ventilation between a group of NMD patients and a group of quadriplegic patients due to ICU-acquired weakness (ICU-AW). METHODS: We prospectively studied 16 subjects with NMD and 26 subjects with ICU-AW ready for weaning, using the method of the re-inhalation of expired air. We measured the hypercapnic drive response, defined as the ratio of change in airway occlusion pressure 0.1 second after the start of inspiration $\left(\Delta \mathrm{P}_{0.1}\right)$ to the change in $\mathrm{PaCO}_{2}\left(\Delta \mathrm{PaCO}_{2}\right)$, and the hypercapnic ventilatory response, defined as the ratio of the change in minute ventilation $(\Delta \dot{\mathrm{V}} \mathrm{E})$ to $\Delta \mathrm{PaCO}_{2}$. We considered a value of $\leq 0.19 \mathrm{~cm} \mathrm{H}_{2} \mathrm{O}$ / $\mathrm{mm} \mathrm{Hg}$ as reduced hypercapnic drive response. RESULTS: Hypercapnic drive response $\left(\Delta \mathbf{P}_{0.1} /\right.$ $\Delta \mathrm{PaCO}_{2}=0.14 \pm 0.08 \mathrm{~cm} \mathrm{H} \mathrm{H}_{2} \mathrm{O} / \mathrm{mm} \mathrm{Hg}$ vs $\left.0.37 \pm 0.27 \mathrm{~cm} \mathrm{H}_{2} \mathrm{O} / \mathrm{mm} \mathrm{Hg}, P=.002\right)$ and hypercapnic ventilatory response $\left(\Delta \dot{\mathrm{V}} / \Delta \mathrm{PaCO}_{2}=0.21 \pm 0.19 \mathrm{~L} / \mathrm{min} / \mathrm{mm} \mathrm{Hg}\right.$ vs $0.44 \pm 0.40 \mathrm{~L} / \mathrm{min} / \mathrm{mm} \mathrm{Hg}$, $P=.02)$ were lower in the NMD than in the ICU-AW subjects. Duration of weaning values, according to the Kaplan-Meier curves, were similar in both groups $($ Log-rank $=0.03, P=.96)$. Eleven NMD (69\%) and $9 \mathrm{ICU}-\mathrm{AW}(35 \%)$ subjects had hypercapnic drive response $\leq 0.19 \mathrm{~cm} \mathrm{H}_{2} \mathrm{O} / \mathrm{mm} \mathrm{Hg}$. The duration of weaning was longer in subjects with hypercapnic drive response $\leq 0.19 \mathrm{~cm} \mathrm{H}_{2} \mathrm{O} / \mathrm{mm} \mathrm{Hg}$ (log-rank $=15.4, P<.001)$. CONCLUSIONS: Subjects with acute hypercapnic respiratory failure due to NMD had reduced hypercapnic drive response, compared to ICU-AW subjects. The duration of weaning was longer in subjects with reduced hypercapnic drive response. Key words: hypercapnia; mechanical ventilation; respiratory center; respiratory function test; neuromuscular diseases; polyneuromyopathy. [Respir Care 2013;58(3):450-457. (c) 2013 Daedalus Enterprises]
\end{abstract}

\section{Introduction}

Neuromuscular function disturbances are a common feature in patients admitted to the ICU. While few patients are admitted because of a primary neuromuscular disease (NMD) with acute respiratory failure, ${ }^{1,2}$ most patients ad-

\footnotetext{
Dr Rialp is affiliated with the Servei de Medicina Intensiva, Hospital Son Llàtzer, Palma de Mallorca, Illes Balears, Spain. Drs Raurich, LlompartPou, Ayestarán, and Ibáñez are affiliated with the Servei de Medicina Intensiva, Hospital Universitari Son Espasas, Palma, Illes Balears, Spain.

The authors have disclosed no conflicts of interest.
}

Correspondence: Joan Maria Raurich MD PhD, Servei de Medicina Intensiva, Hospital Universitari Son Espases, Carretera Valldemossa 79, Palma, Illes Balears 07010 Spain. E-Mail: joan.raurich@ssib.es.

DOI: $10.4187 /$ respcare. 01873 mitted to the ICU due to different medical or surgical reasons develop ICU-acquired weakness (ICU-AW), ${ }^{3-5}$ which is associated with weaning failure of mechanical ventilation. 6,7

Weakness of the respiratory muscles leads to hypercapnic respiratory failure. ${ }^{8,9}$ The acute hypercapnic respiratory failure in NMD patients and the weaning failure in ICU-AW patients are attributable to the acute inspiratory muscles weakness or a relatively trivial increase in mechanical ventilatory load, such as mild airway obstruction, atelectasis, or infection. ${ }^{6,7}$ The contribution of the central respiratory drive in the respiratory failure in both situations has not been fully established yet.

The central respiratory drive can be evaluated measuring the hypercapnic drive response as a change in the airway occlusion pressure 0.1 second after the start of inspiration $\left(\mathrm{P}_{0.1}\right)$ induced by the increase in $\mathrm{PaCO}_{2}$. While some studies in NMD found that the hypercapnic drive 
response is usually preserved in stable patients ${ }^{10,11}$ and in patients with acute respiratory failure, ${ }^{12}$ a reduced hypercapnic drive response in stable myasthenia gravis patients, compared to normal subjects, has also been described. ${ }^{13}$ The depressed central respiratory drive in some NMD patients has also been associated with a poor relationship between respiratory muscle strength and the level of $\mathrm{PaCO}_{2},{ }^{14,15}$ with the occurrence of daytime hypersomnolence, ${ }^{14}$ or with central hypoventilation. ${ }^{16}$ In ICU-AW patients who fail weaning trials, the central respiratory drive has not yet been studied.

We evaluated 2 different models of neuromuscular dysfunction, one at admission (NMD group), and the other acquired during ICU stay (ICU-AW group). The objective of this prospective study was to compare the $\mathrm{CO}_{2}$ response and the duration of weaning from mechanical ventilation between a group of NMD patients and a group of patients with quadriplegia due to ICU-AW.

\section{Methods}

\section{Subjects}

In 2 medical-surgical ICUs we prospectively studied non-consecutive subjects mechanically ventilated due to acute hypercapnic respiratory failure secondary to NMD (16 subjects) or with weaning failure secondary to ICU-AW quadriplegia (26 subjects). The study was conducted from July 2004 to November 2009, and was approved by the review boards of both hospitals. Informed consent was obtained in all cases from the subject or closest relative.

The different NMDs were diagnosed by clinical, physical examination, electromyogram, imaging, and laboratory tests. ${ }^{2}$ According to the Brussels round table conference, ${ }^{3}$ the ICU-AW group included subjects who developed weakness in the course of treatment of an acute illness syndrome such as sepsis and/or respiratory failure. Subjects with quadriplegia due to ICU-AW were identified in awakening subjects after the acute phase of critical illness by using the simple bedside limb muscle strength score of the Medical Research Council. ${ }^{17}$ In these subjects, quadriplegia was considered when 12 muscle groups in upper (wrist extension, elbow flexion, and shoulder abduction) and lower extremities (dorsiflexion of the foot, knee extension, hip flexion) were tested showing no muscular contraction or barely detectable flicker or trace of contraction.

\section{Protocol}

Subjects were studied when the physician in charge considered that they were clinically stable and fulfilled criteria for a spontaneous breathing trial. These criteria included that the subject was hemodynamically stable, awake without sedation, and able to obey oral commands,

\section{QUICK LOOK}

\section{Current knowledge}

Respiratory muscle weakness in patients with neuromuscular disease or ICU-acquired weakness results in hypercapnia. Minor increases in ventilatory load in these patients can precipitate the need for mechanical ventilation or result in weaning failure. While the impact of respiratory muscle weakness in these patients is well known, the contribution of central respiratory drive is not well defined.

\section{What this paper contributes to our knowledge}

Subjects with acute hypercapnic respiratory failure secondary to neuromuscular disease had a reduced hypercapnic drive response, compared to subjects with ICU-acquired weakness. Reduced hypercapnic respiratory drive was associated with prolonged weaning from mechanical ventilation.

core temperature below $38.3^{\circ} \mathrm{C}$, and had a $\mathrm{PaO}_{2} / \mathrm{FIO}_{2}$ above $150 \mathrm{~mm} \mathrm{Hg}$ with a PEEP of $\leq 8 \mathrm{~cm} \mathrm{H}_{2} \mathrm{O} .{ }^{18}$ Patients were not studied if they had a diagnosis of COPD.

When the subjects were clinically stable and ready for a spontaneous breathing trial, respiratory neuromuscular function was evaluated by measurement of maximal inspiratory pressure $\left(\mathrm{P}_{\text {Imax }}\right)$, maximal expiratory pressure $\left(\mathrm{P}_{\text {Emax }}\right)$, and $\mathrm{CO}_{2}$ response test. All these measurements were carried out in the semirecumbent position at $30^{\circ}$. We continuously recorded electrocardiogram, heart rate, pulse oximetry, and invasive systemic blood pressure.

\section{Measurements and Procedures}

Maximal Inspiratory and Expiratory Pressure. $P_{\text {Imax }}$ and $\mathrm{P}_{\mathrm{Emax}}$ were measured, after 1-2 min of spontaneous breathing, with an external pressure transducer, via a unidirectional valve (Hans Rudolph, Kansas City, Missouri) connected to the endotracheal tube. $\mathrm{P}_{\mathrm{Imax}}$ was obtained at residual volume by occluding the inspiratory port of the unidirectional valve, whereas $\mathrm{P}_{\text {Emax }}$ was measured at total lung volume by occluding the expiratory port. ${ }^{19}$ After 20 25 seconds of occluded inspiration or expiration, the most negative or positive pressure values were recorded for $\mathrm{P}_{\text {Imax }}$ or $\mathrm{P}_{\text {Emax }}$ test. Two measurements were performed and the highest value was used for analysis.

\section{$\mathrm{CO}_{2}$ Response Test}

To increase the $\mathrm{CO}_{2}$ we used the method of the reinhalation of expired air, ${ }^{20-22}$ by inserting a $22 \mathrm{~mm}$ cor- 


\section{Central Respiratory Drive in Patients With Neuromuscular Diseases}

Table 1. Clinical Characteristics

\begin{tabular}{|c|c|c|c|}
\hline & $\begin{array}{c}\text { Neuromuscular } \\
\text { Disease } \\
(n=16)\end{array}$ & $\begin{array}{c}\text { ICU-Acquired } \\
\text { Weakness } \\
(n=26)\end{array}$ & $P$ \\
\hline Age, mean \pm SD y & $53 \pm 20$ & $61 \pm 12$ & .14 \\
\hline Female, no. $(\%)$ & $10(62)$ & $11(42)$ & .34 \\
\hline Weight, mean $\pm \mathrm{SD} \mathrm{kg}$ & $72 \pm 13$ & $74 \pm 15$ & .60 \\
\hline Height, mean $\pm \mathrm{SD} \mathrm{cm}$ & $162 \pm 7$ & $166 \pm 10$ & .22 \\
\hline Body mass index, mean $\pm \mathrm{SD} \mathrm{kg} / \mathrm{m}^{2}$ & $27.9 \pm 4.5$ & $26.7 \pm 6.1$ & .53 \\
\hline Diabetes, no. $(\%)$ & $4(25)$ & $6(23)$ & $>.99$ \\
\hline SAPS II at ICU admission, mean $\pm \mathrm{SD}$ & $40 \pm 15$ & $48 \pm 13$ & .047 \\
\hline \multicolumn{4}{|l|}{ Main Diagnosis, no. (\%) } \\
\hline Myasthenia gravis & $6(38)$ & - & \\
\hline Guillain-Barré & $3(19)$ & - & \\
\hline Organophosphate poisoning & $2(12)$ & - & \\
\hline Other neuromuscular diseases* & $5(31)$ & - & \\
\hline Pneumonia & - & $16(62)$ & \\
\hline Non-pulmonary sepsis & - & $6(23)$ & \\
\hline Postoperative state & - & $3(11)$ & \\
\hline Acute asthma & - & $1(4)$ & \\
\hline Tracheostomy, no. $(\%)$ & $7(44)$ & $18(69)$ & .10 \\
\hline Ventilation duration before study day, median (IQR) d & $2.5(1-5)$ & $18(15-32)$ & $<.001$ \\
\hline Weaning duration, median (IQR) d & $14(3-23)$ & $9(3-31)$ & .89 \\
\hline ICU stay, median (IQR) d & $22(11-36)$ & $46(27-70)$ & .01 \\
\hline In-hospital stay, median (IQR) d & $39(23-85)$ & $79(38-110)$ & .02 \\
\hline ICU mortality, no. (\%) & $2(12)$ & $5(19.2)$ & 69 \\
\hline In-hospital mortality, no. (\%) & $6(37.5)$ & $11(42.3)$ & .76 \\
\hline
\end{tabular}

rugated tube (Corr-a-Flex II, Hudson RCI/Teleflex Medical, Research Triangle Park, North Carolina) between the $\mathrm{Y}$-piece and the endotracheal tube, which increased the dead space with a volume similar to the tidal volume obtained with a pressure support of $7 \mathrm{~cm} \mathrm{H}_{2} \mathrm{O}$ in each subject.

Baseline values for $\mathrm{CO}_{2}$ response test were obtained after applying $5 \mathrm{~min}$ of pressure support ventilation with a pressure of $7 \mathrm{~cm} \mathrm{H}_{2} \mathrm{O}$, without $\mathrm{PEEP}$, and $\mathrm{FIO}_{2}$ was set at 1.0 to prevent hypoxemia for subjects' security and to avoid hypoxic stimuli. Then, breathing frequency, $\mathrm{P}_{0.1}$, and minute ventilation $\left(\dot{V}_{E}\right)$ were recorded from the ventilator, and an arterial blood sample was withdrawn. Thereafter we initiated the $\mathrm{CO}_{2}$ response test by increasing dead space, maintaining the same ventilatory support, and when the exhaled $\mathrm{CO}_{2}$ (measured through capnography) had increased by above $10 \mathrm{~mm} \mathrm{Hg}$, we again measured breathing frequency, $\mathrm{P}_{0.1}$, and $\dot{\mathrm{V}}_{\mathrm{E}}$, and withdrew another arterial blood sample. Once the $\mathrm{CO}_{2}$ response test was finished, the added dead space was removed and the subject was returned to his original assisted ventilation mode.

We studied the following derived indices of $\mathrm{CO}_{2}$ response test: the hypercapnic drive response, defined as the ratio of the change in $\mathrm{P}_{0.1}\left(\Delta \mathrm{P}_{0.1}\right)$ to the change in $\mathrm{PaCO}_{2}$
$\left(\Delta \mathrm{PaCO}_{2}\right)$, and the hypercapnic ventilatory response, defined as the ratio of $\Delta \dot{\mathrm{V}} \mathrm{E}$ to $\Delta \mathrm{PaCO}_{2}$. The changes in $\dot{\mathrm{V}}$, $\mathrm{P}_{0.1}$, and $\mathrm{PaCO}_{2}$ were calculated as the difference between the value at the end of the $\mathrm{CO}_{2}$ response test and the baseline value. $\mathrm{P}_{0.1}$ was measured by means of the built-in system of the ventilator (Evita 2 Dura or Evita 4, Dräger, Lübeck, Germany), ${ }^{23,24}$ and $\mathrm{P}_{0.1}$ was calculated as the mean of 5 measurements at each point of the study. ${ }^{25}$ Arterial blood gases were measured with a blood gas analyzer (IL-1650, Instrument Laboratory, Izasa, Spain).

\section{Data Collection and Definitions}

We recorded the following clinical variables: sex, age, height, weight, presence of diabetes, the Simplified Acute Physiological Score II, duration of mechanical ventilation before the study day, number of tracheotomized subjects, ICU and in-hospital stay, and ICU and in-hospital mortality. The etiology of NMD and the main diagnosis in the ICU-AW subjects were also recorded. In subjects with NMD, arterial blood gases (when available) were recorded before initiating mechanical ventilation.

We considered the study day as the day that the $\mathrm{CO}_{2}$ response test was performed. We considered a value $\leq$ 
Table 2. Baseline Ventilatory Parameters, Arterial Blood Gases, and Respiratory Neuromuscular Function on the Study Day

\begin{tabular}{|c|c|c|c|}
\hline & $\begin{array}{c}\text { Neuromuscular } \\
\text { Disease } \\
(n=16)\end{array}$ & $\begin{array}{l}\text { ICU-Acquired } \\
\text { Weakness } \\
(n=26)\end{array}$ & $P$ \\
\hline \multicolumn{4}{|l|}{ Baseline Arterial Blood Gases } \\
\hline $\mathrm{pH}$ & $7.38 \pm 0.06$ & $7.42 \pm 0.06$ & .08 \\
\hline $\mathrm{PaO}_{2} / \mathrm{FIO}_{2}, \mathrm{~mm} \mathrm{Hg}$ & $360 \pm 109$ & $446 \pm 101$ & .01 \\
\hline $\mathrm{HCO}_{3}^{-}, \mathrm{mmol} / \mathrm{L}$ & $26.3 \pm 3.0$ & $26.1 \pm 3.1$ & .82 \\
\hline \multicolumn{4}{|l|}{$\mathrm{CO}_{2}$ Response Test } \\
\hline Added dead space, $\mathrm{mL}$ & $393 \pm 101$ & $401 \pm 71$ & .76 \\
\hline \multicolumn{4}{|l|}{ Breathing frequency, breaths/min } \\
\hline Baseline & $24 \pm 7$ & $31 \pm 8$ & .005 \\
\hline Hypercapnia & $29 \pm 6$ & $36 \pm 9$ & .005 \\
\hline \multicolumn{4}{|l|}{$\mathrm{P}_{0.1}, \mathrm{~cm} \mathrm{H}_{2} \mathrm{O}$} \\
\hline Baseline & $2.2 \pm 1.4$ & $3.7 \pm 1.8$ & .01 \\
\hline Hypercapnia & $5.0 \pm 2.5$ & $9.2 \pm 4.5$ & $<.001$ \\
\hline \multicolumn{4}{|l|}{ Minute Ventilation, L/min } \\
\hline Baseline & $8.0 \pm 2.2$ & $11.7 \pm 2.8$ & $<.001$ \\
\hline Hypercapnia & $11.8 \pm 4.3$ & $17.6 \pm 5.7$ & .001 \\
\hline \multicolumn{4}{|l|}{$\mathrm{PaCO}_{2}, \mathrm{~mm} \mathrm{Hg}$} \\
\hline Baseline & $44.8 \pm 5.4$ & $39.0 \pm 7.7$ & .01 \\
\hline Hypercapnia & $65.1 \pm 7.9$ & $54.9 \pm 10.7$ & .002 \\
\hline \multicolumn{4}{|l|}{ Respiratory Neuromuscular Function } \\
\hline $\mathrm{P}_{\text {Emax }}, \mathrm{cm} \mathrm{H}_{2} \mathrm{O}$ & $18 \pm 11$ & $23 \pm 11$ & .19 \\
\hline $\mathrm{P}_{\text {Imax }}, \mathrm{cm} \mathrm{H}_{2} \mathrm{O}$ & $29 \pm 16$ & $45 \pm 19$ & .01 \\
\hline$\Delta \mathrm{P}_{0.1} / \Delta \mathrm{PaCO}_{2}, \mathrm{~cm} \mathrm{H}_{2} \mathrm{O} / \mathrm{mm} \mathrm{Hg}$ & $0.14 \pm 0.08$ & $0.37 \pm 0.27$ & .002 \\
\hline$\Delta \dot{\mathrm{V}} / \Delta \mathrm{PaCO}_{2}, \mathrm{~L} / \mathrm{min} / \mathrm{mm} \mathrm{Hg}$ & $0.21 \pm 0.19$ & $0.44 \pm 0.40$ & .02 \\
\hline $\begin{array}{l}\mathrm{P}_{0.1}=\text { occlusion pressure } 0.1 \mathrm{~s} \text { after the start of } \\
\mathrm{P}_{\text {Emax }}=\text { maximal expiratory pressure } \\
\mathrm{P}_{\text {Imax }}=\text { maximal inspiratory pressure } \\
\Delta \mathrm{P}_{0.1} / \Delta \mathrm{PaCO}_{2}=\text { hypercapnic drive response } \\
\Delta \mathrm{V}_{\mathrm{E}} / \Delta \mathrm{PaCO}_{2}=\text { hypercapnic ventilatory response }\end{array}$ & & & \\
\hline
\end{tabular}

$0.19 \mathrm{~cm} \mathrm{H}_{2} \mathrm{O} / \mathrm{mm} \mathrm{Hg}$ as reduced hypercapnic drive response. $^{26}$ Duration of mechanical ventilation before the study day was defined as the number of days between the beginning of mechanical ventilation and the day the $\mathrm{CO}_{2}$ response test was performed. Subjects were followed until discharge from our 2 hospitals.

\section{Statistical Analysis}

Categorical data are expressed as number and percentages. Continuous variables are expressed as mean \pm standard deviation or as median and interquartile ranges (IQR). Differences between groups were compared with the paired $t$ test or the Mann-Whitney test and chi-square test or Fisher exact test, when appropriate. We used linear regression to establish the association between $\mathrm{P}_{\text {Imax }}$ and hypercapnic drive response and hypercapnic ventilatory response. We used the Kaplan-Meier method and the log-rank test to estimate differences in the duration of weaning between the groups of subjects and for the threshold value of hypercapnic drive response. Statistical analysis was per- formed with specific statistics software (SPSS 17.0, SPSS, Chicago, Illinois).

\section{Results}

The etiology of the NMD and the underlying diagnosis in ICU-AW subjects are summarized in Table 1. We found no differences between the NMD and ICU-AW groups, except for the Simplified Acute Physiological Score II, the duration of mechanical ventilation before study day, and ICU and in-hospital stay (see Table 1). In 12 subjects with NMD we obtained a sample for measuring arterial blood gases before mechanical ventilation. Mean $\mathrm{pH}$ was $7.20 \pm 0.11$ and $\mathrm{PaCO}_{2}$ was $86 \pm 28 \mathrm{~mm} \mathrm{Hg}$. The other 4 NMD subjects received invasive mechanical ventilation before arterial blood samples were drawn.

Subjects with NMD had lower baseline $\mathrm{PaO}_{2} / \mathrm{FIO}_{2}$, breathing frequency, $\mathrm{P}_{0.1}$, and $\mathrm{V}_{\mathrm{E}}$, and higher $\mathrm{PaCO}_{2}$ than ICU-AW subjects, with no differences in $\mathrm{pH}$, bicarbonate, and volume of added dead space (Table 2). Inspiratory neuromuscular function evaluated by $\mathrm{P}_{\text {Imax }}$, hypercapnic 


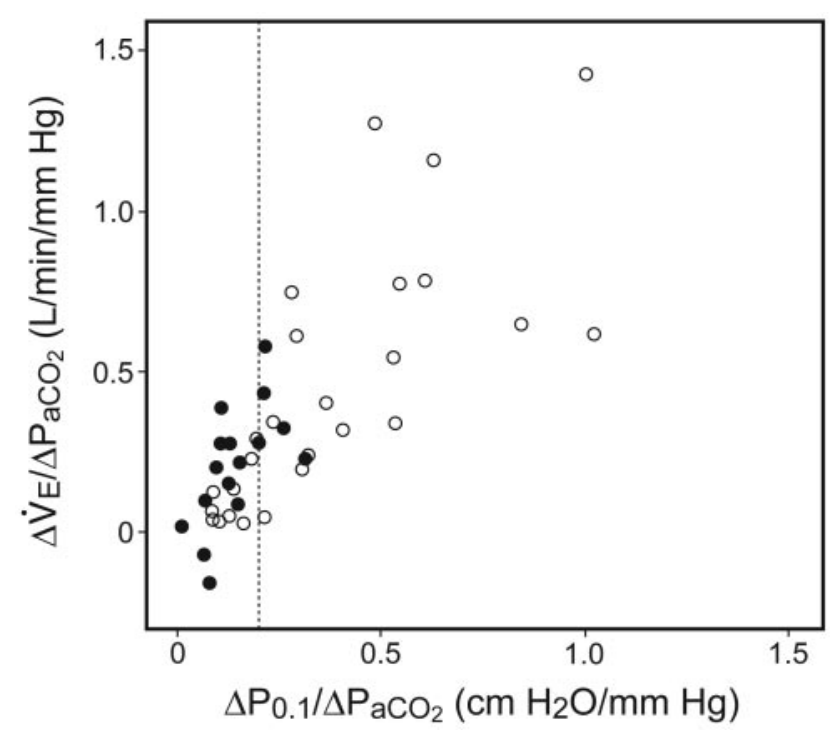

Fig. 1. Hypercapnic drive response (the ratio of the change in airway-occlusion pressure $0.1 \mathrm{~s}$ after the start of inspiratory flow $\left[\Delta \mathrm{P}_{0.1}\right]$ to $\left.\Delta \mathrm{Paco}_{2}\right]$ ) and hypercapnic ventilatory response (the ratio of the change in minute ventilation $\left[\Delta \dot{\mathrm{V}}_{\mathrm{E}}\right]$ to $\Delta \mathrm{PacO}_{2}$ ) in neuromuscular diseases (black circles) and in ICU-acquired weakness (white circles). The dotted line represents the cutoff value of $\Delta \mathrm{P}_{0.1} / \Delta \mathrm{PaCO}_{2}$ of $0.19 \mathrm{~cm} \mathrm{H}_{2} \mathrm{O} / \mathrm{mm} \mathrm{Hg}$.

drive response $\left(\Delta \mathrm{P}_{0.1} / \Delta \mathrm{PaCO}_{2}\right)$, and hypercapnic ventilatory response $\left(\Delta \dot{\mathrm{V}}_{\mathrm{E}} / \Delta \mathrm{PaCO}_{2}\right)$ were significantly lower in the NMD than in the ICU-AW subjects (see Table 2 and Fig. 1). Expiratory muscle strength evaluated by $\mathrm{P}_{\mathrm{Emax}}$ was low in both groups, without significant statistical differences (see Table 2). There was a weak association between $\mathrm{P}_{\text {Imax }}$ and the hypercapnic drive response $\left(\mathrm{r}^{2}=0.31\right.$, $P>.001)$ and the hypercapnic ventilatory response $\left(\mathrm{r}^{2}=0.15, P=.01\right)$ (Fig. 2).

The duration of weaning, evaluated by Kaplan-Meier curves (Fig. 3), was similar in both groups (log-rank $=$ $0.03, P=.96)$. Eleven subjects $(69 \%)$ in the NMD group and 9 subjects $(35 \%)$ in the ICU-AW group had hypercapnic drive response $\leq 0.19 \mathrm{~cm} \mathrm{H}_{2} \mathrm{O} / \mathrm{mm} \mathrm{Hg}$ (Table 3). When analyzed, each group, NMD or ICU-AW, according to the $\mathrm{CO}_{2}$ response, weaning was shorter in subjects with hypercapnic drive response $>0.19 \mathrm{~cm} \mathrm{H}_{2} \mathrm{O} / \mathrm{mm} \mathrm{Hg}$ than in subjects with hypercapnic drive response $\leq 0.19 \mathrm{~cm}$ $\mathrm{H}_{2} \mathrm{O} / \mathrm{mm} \mathrm{Hg}$, with significant differences in the ICU-AW group (log-rank $=14.0, P<.001)$, but not in the NMD group (log-rank $=2.1, P=.14$ ) (see Fig. 3). For both groups the duration of weaning was longer in subjects with hypercapnic drive response $\leq 0.19 \mathrm{~cm} \mathrm{H}_{2} \mathrm{O} / \mathrm{mm} \mathrm{Hg}$ (logrank $=15.4, \mathrm{p}<.001)$.

\section{Discussion}

The main results of the study were that the hypercapnic drive response was reduced in NMD patients recovering
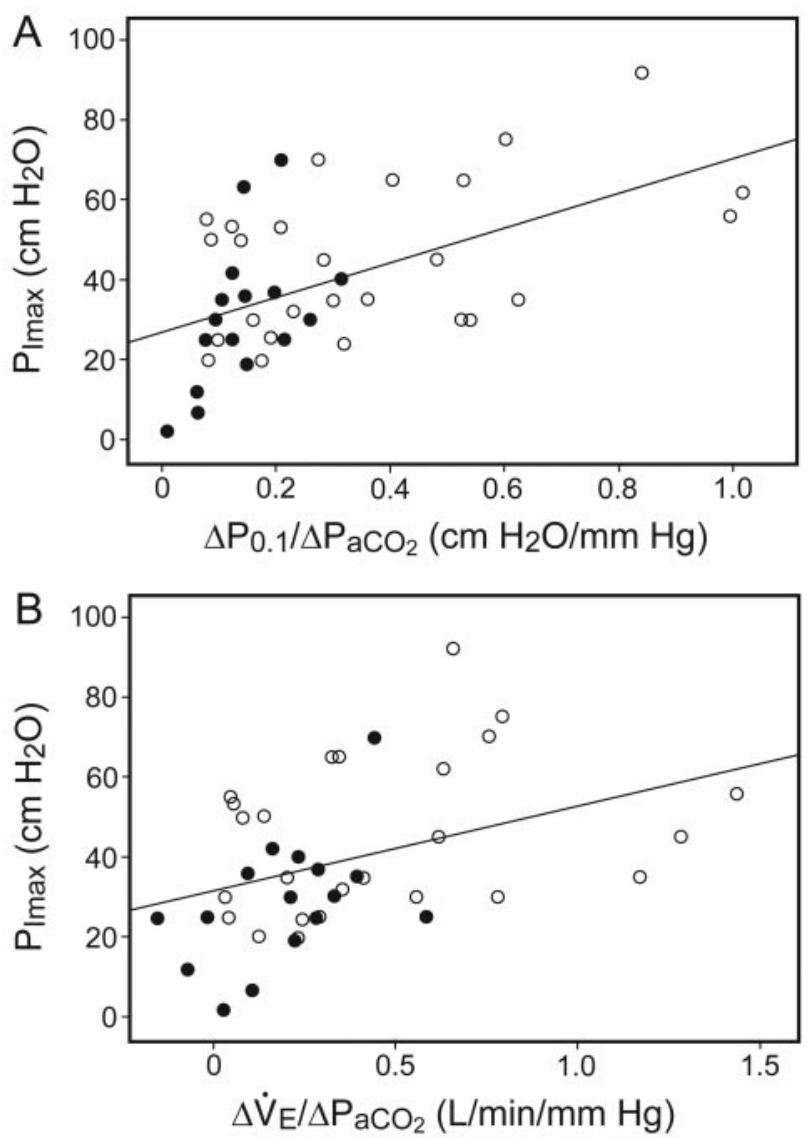

Fig. 2. A: Relationships between $(A)$ the hypercapnic drive response (the ratio of the change in airway-occlusion pressure $0.1 \mathrm{~s}$ after the start of inspiratory flow $\left[\Delta \mathrm{P}_{0.1}\right]$ to $\left.\Delta \mathrm{PacO}_{2}\right)$ and $(\mathrm{B})$ the hypercapnic ventilatory response (the ratio of the change in minute ventilation $\left[\Delta \dot{\mathrm{V}}_{\mathrm{E}}\right]$ to $\Delta \mathrm{PaCO}_{2}$ ) with maximal inspiratory pressure $\left(P_{\text {Imax }}\right)$. The black circles represent the neuromuscular diseases group, and the white circles represent the ICU-acquired weakness group.

from acute hypercapnic respiratory failure, while it was preserved in most ICU-AW patients presenting with weaning failure. In both groups of subjects the duration of weaning was longer when the hypercapnic drive response was reduced. However, these affirmations should be considered with caution, since both groups were not comparable in all baseline characteristics, including the underlying cause of mechanical ventilation.

The acute respiratory failure in the NMD group was associated with respiratory muscle weakness, as shown by low values of $\mathrm{P}_{\mathrm{Imax}}$ and $\mathrm{P}_{\mathrm{Emax}}$. However, a severe reduction of the hypercapnic drive response in the majority of subjects was also observed. These data suggest that the respiratory muscle weakness itself explained only part of the respiratory failure in the NMD subjects. The weak association between hypercapnic drive response and respiratory muscle weakness reflects the different contribution of each mechanism for a given subject. 

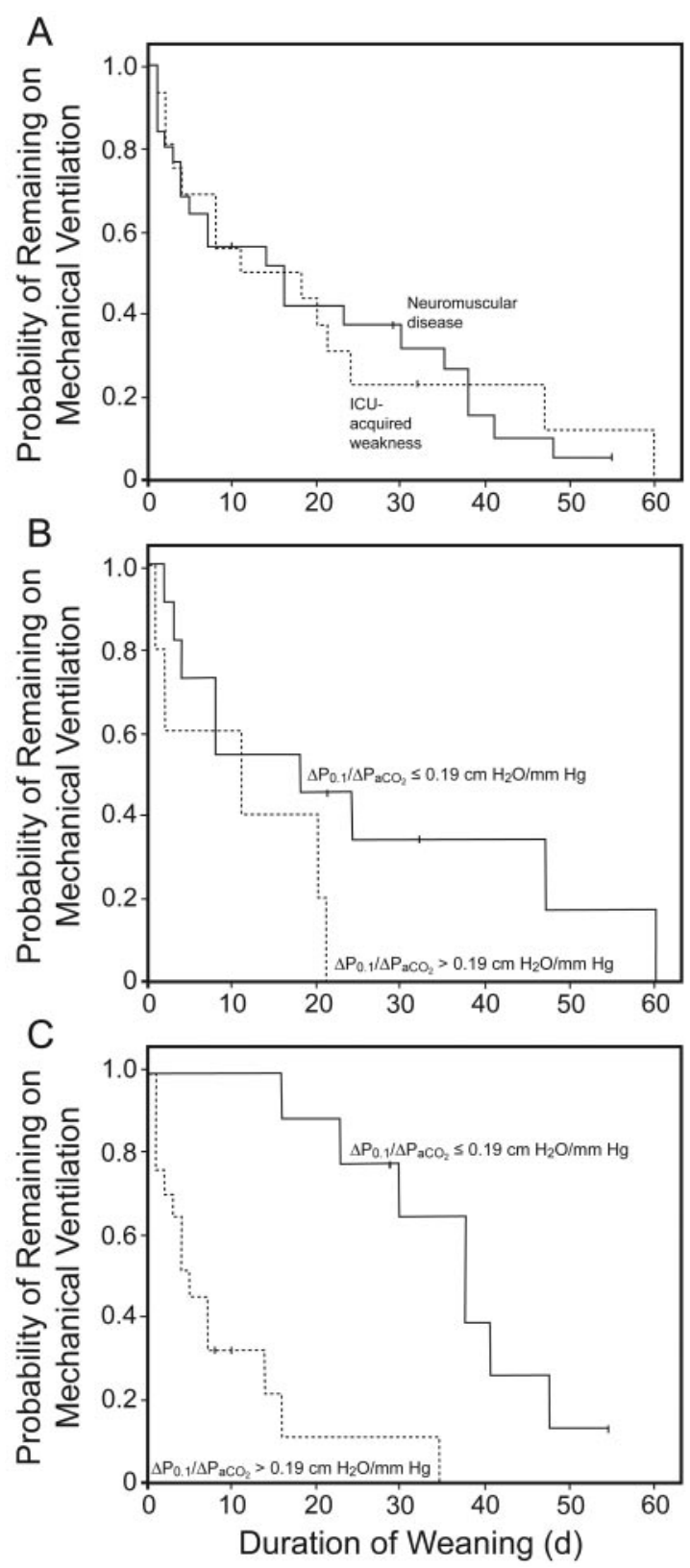

Fig. 3. Kaplan-Meier curves representing the probability of remaining on mechanical ventilation after the day of the $\mathrm{CO}_{2}$ response test (A) for neuromuscular diseases (continuous line) and ICUacquired weakness (dotted line), (B) for the neuromuscular disease group, and (C) for the ICU-acquired weakness group, according to the hypercapnic drive response (the ratio of the change in airway-occlusion pressure $0.1 \mathrm{~s}$ after the start of inspiratory flow $\left[\Delta \mathrm{P}_{0.1}\right]$ to $\left.\Delta \mathrm{PacO}_{2}\right) \leq 0.19 \mathrm{~cm} \mathrm{H} \mathrm{O} / \mathrm{mm} \mathrm{Hg}$ (continuous line) and $>0.19 \mathrm{~cm} \mathrm{H} \mathrm{H}_{2} \mathrm{O} / \mathrm{mm} \mathrm{Hg}$ (dotted line).

Eleven subjects $(69 \%)$ of the NMD group had a hypercapnic drive response value $\leq 0.19 \mathrm{~cm} \mathrm{H}_{2} \mathrm{O} / \mathrm{mm} \mathrm{Hg}$. The low mean value of hypercapnic drive response $\left(0.24 \pm 0.05 \mathrm{~cm} \mathrm{H}_{2} \mathrm{O} / \mathrm{mm} \mathrm{Hg}\right)$ of the $5 \mathrm{NMD}$ subjects with hypercapnic drive response $>0.19 \mathrm{~cm} \mathrm{H}_{2} \mathrm{O} / \mathrm{mm} \mathrm{Hg}$ may explain why there were no statistical differences in the duration of weaning among NMD subjects with hypercapnic drive response above and below the cutoff value. Although it is unknown which level of hypercapnic drive response should be considered clinically low, a cutoff value of $\leq 0.19 \mathrm{~cm} \mathrm{H}_{2} \mathrm{O} / \mathrm{mm} \mathrm{Hg}$ has recently been associated with prolonged weaning. ${ }^{26}$

The ICU-AW subjects, differently from the NMD group, had higher baseline $\mathrm{P}_{0.1}$ and were able to increase the $\mathrm{P}_{0.1}$ with hypercapnic stimulation, in spite of presenting with quadriplegia. The mean hypercapnic drive response value found in these subjects was only moderately lower than that previously reported in healthy subjects, $0.6 \pm 0.5 \mathrm{~cm} \mathrm{H}_{2} \mathrm{O} / \mathrm{mm} \mathrm{Hg}, 27$ and only 9 subjects (35\%) had a hypercapnic drive response value $\leq 0.19 \mathrm{~cm} \mathrm{H}_{2} \mathrm{O} /$ $\mathrm{mm} \mathrm{Hg}$.

To our knowledge, only one study measured the hypercapnic drive response in NMD patients recovering from acute respiratory failure. ${ }^{12}$ Contrary to our results, Borel et $\mathrm{al}^{12}$ found that the hypercapnic drive response remained intact in 73 trials of spontaneous breathing performed in 4 patients with Guillain-Barré and 3 patients with myasthenia gravis. However, failed trials showed lower values of hypercapnic drive response, compared to successful trials, and, thus, those patients who failed the spontaneous breathing trial had low values of hypercapnic drive response, in agreement with our results.

Reduced hypercapnic drive response represents a reduction in sensitivity of chemoreceptors to chemical $\mathrm{CO}_{2}$ stimuli. The cause of reduced sensitivity can be idiopathic in $10-15 \%$ of healthy subjects, ${ }^{27}$ or acquired in patients with acute or chronic diseases, as occurs in patients with diabetic autonomic neuropathy. In these patients it has been reported that there is a relationship between a predominant parasympathetic involvement and a reduced cerebrovascular $\mathrm{CO}_{2}$ reactivity and reduced $\mathrm{P}_{0.1}$ response to $\mathrm{CO}_{2} \cdot{ }^{28}$

Autonomic neuropathy or dysfunction has been described in many other diseases, including NMD ${ }^{29}$ and multiple organ dysfunction syndrome. ${ }^{30,31}$ We hypothesize that autonomic neuropathy associated with a reduced sensitivity of chemoreceptors could explain the reduced hypercapnic drive response in most of our NMD and some ICU-AW subjects. In spite of that, autonomic neuropathy is not a clinical feature of ICU-AW patients ${ }^{32}$; most of ICU-AW patients have multiple organ dysfunction syndrome, and this feature can play a role in the reduced $\mathrm{CO}_{2}$ response we found. Additionally, other causes of autonomic neuropathy can be present. In our study, 4 out of 9 subjects with ICU-AW and hypercapnic drive response $\leq 0.19 \mathrm{~cm} \mathrm{H}_{2} \mathrm{O} / \mathrm{mm} \mathrm{Hg}$ had diabetes. Further studies are needed to confirm the hypothesis of association between autonomic neuropathy and reduced $\mathrm{CO}_{2}$ response. Interestingly, and in favor of this hypothesis, autonomic instability and bulbar dysfunction predicted the development 


\section{Central Respiratory Drive in Patients With Neuromuscular Diseases}

Table 3. Hypercapnic Drive Response

\begin{tabular}{|c|c|c|c|c|c|}
\hline & \multicolumn{2}{|c|}{$\begin{array}{l}\text { Neuromuscular } \\
\text { Disease }\end{array}$} & \multicolumn{2}{|c|}{$\begin{array}{l}\text { ICU-Acquired } \\
\text { Weakness }\end{array}$} & \multirow[t]{2}{*}{$P$} \\
\hline & $n$ & $\Delta \mathrm{P}_{0.1} / \Delta \mathrm{PaCO}_{2}$ & $n$ & $\Delta \mathrm{P}_{0.1} / \Delta \mathrm{PaCO}_{2}$ & \\
\hline$\Delta \mathrm{P}_{0.1} / \Delta \mathrm{PaCO}_{2} \leq 0.19 \mathrm{~cm} \mathrm{H}_{2} \mathrm{O} / \mathrm{mm} \mathrm{Hg}$ & 11 & $0.10 \pm 0.04$ & 9 & $0.13 \pm 0.04$ & .21 \\
\hline$\Delta \mathrm{P}_{0.1} / \Delta \mathrm{PaCO}_{2}>0.19 \mathrm{~cm} \mathrm{H}_{2} \mathrm{O} / \mathrm{mm} \mathrm{Hg}$ & 5 & $0.24 \pm 0.05$ & 17 & $0.50 \pm 0.25$ & .007 \\
\hline \multicolumn{6}{|c|}{$\begin{array}{l}\mathrm{P}_{0.1}=\text { occlusion pressure } 0.1 \mathrm{~s} \text { after the start of inspiratory flow } \\
\Delta \mathrm{P}_{0.1} / \Delta \mathrm{PaCO}_{2}=\text { hypercapnic drive response }\end{array}$} \\
\hline
\end{tabular}

of neuromuscular respiratory paralysis in patients with Guillain-Barré syndrome. ${ }^{33-35}$

A potential drawback of our study is based on the influence of sedatives in our results. Although both groups differed in the type and dose of sedatives, this is not likely to be determinant for our conclusions because the NMD subjects, who had a more blunted $\mathrm{CO}_{2}$ response, received very short-acting sedatives within a median (IQR) of 2.5 (15) days of onset of mechanical ventilation, compared with ICU-AW, who received long-acting sedatives a median (IQR) of 18 (15-32) days.

Our study has several limitations. First, we studied a small number of subjects in each group, and, in addition, the NMD group was heterogeneous and both groups were not comparable in baseline characteristics. Therefore, it is necessary to perform larger trials of a more homogeneous population to confirm our results. Second, we measured $\mathrm{P}_{0.1}$ through the ventilators, instead of with the conventional method. ${ }^{36}$ The Evita ventilator shows a trend to overestimate high $\mathrm{P}_{0.1}$ values and to underestimate low $\mathrm{P}_{0.1}$ values. ${ }^{24}$ However, $\mathrm{CO}_{2}$ response evaluates the $\dot{\mathrm{V}} \mathrm{E}$ and $\mathrm{P}_{0.1}$ changes induced by a $\mathrm{CO}_{2}$ increase, not the absolute $\dot{V}_{E}$ and $\mathrm{P}_{0.1}$ values, so the systematic error may be reduced. And, third, we have not performed autonomic function tests to evaluate the activity of the autonomic nervous system.

\section{Conclusions}

In conclusion, subjects with acute hypercapnic respiratory failure due to NMD had reduced hypercapnic drive response, compared to quadriplegic subjects secondary to ICU-AW. The duration of weaning was longer in subjects with reduced hypercapnic drive response.

\section{REFERENCES}

1. Ali MI, Fernandez-Perez ER, Pendem S, Brown DR, Wijdicks EF, Gajic O. Mechanical ventilation in patients with Guillain-Barré syndrome. Respir Care 2006;51(12):1403-1407.

2. Crone C, Krarup C. Diagnosis of acute neuropathies. J Neurol 2007; 254(9):1151-1169.
3. Griffiths RD, Hall JB. Intensive care unit-acquired weakness. Crit Care Med 2010;38(3):779-787.

4. Deem S. Intensive-care-unit-acquired muscle weakness. Respir Care 2006;51(9):1042-1052.

5. Ali NA, O’Brien JM Jr, Hoffmann SP, Phillips G, Garland A, Finley JC, et al. Acquired weakness, handgrip strength, and mortality in critically ill patients. Am J Respir Crit Care Med 2008;178(3): 261-268.

6. Garnacho-Montero J, Amaya-Villar R, García-Garmendía JL, Madrazo-Osuna J, Ortiz-Leyba C. Effect of critical illness polyneuropathy on the withdrawal from mechanical ventilation and the length of stay in septic patients. Crit Care Med 2005;33(2):349-354.

7. De Jonghe B, Bastuji-Garin S, Durand MC, Malissin I, Rodrigues P, Cerf $\mathrm{C}$ et al. Respiratory weakness is associated with limb weakness and delayed weaning in critical illness. Crit Care Med 2007;35(9): 2007-2015.

8. Roussos C, Koutsoukou A. Respiratory failure. Eur Respir J 2003; 47(Suppl):3S-14S.

9. Mehta S. Neuromuscular disease causing acute respiratory failure. Respir Care 2006;51(9):1016-1021.

10. Begin R, Bureau MA, Lupien L, Lemieux B. Control and modulation of respiration in Steinert's myotonic dystrophy. Am Rev Respir Dis 1980;121(2):281-289.

11. Begin R, Bureau MA, Lupien L, Bernier JP, Lemieux B. Pathogenesis of respiratory insufficiency in myotonic dystrophy: the mechanical factors. Am Rev Respir Dis 1982;125(3):312-318.

12. Borel C, Teitelbaum J, Hanley D. Ventilatory drive and carbon dioxide response in ventilatory failure due to myasthenia gravis and Guillain-Barré syndrome. Crit Care Med 1993;21(11):1717-1726.

13. Spinelli A, Marconi G, Gorini M, Pizzi A, Scano G. Control of breathing in patients with myasthenia gravis. Am Rev Respir Dis 1992;145(6):1359-1366.

14. Begin P, Mathieu J, Almirall J, Grassino A. Relationship between chronic hypercapnia and inspiratory-muscle weakness in myotonic dystrophy. Am J Respir Crit Care Med 1997;156(1):133-139.

15. Lyall RA, Donaldson N, Polkey MI, Leigh PN, Moxham J. Respiratory muscle strength and ventilatory failure in amyotrophic lateral sclerosis. Brain 2001;124(Pt 10):2000-2013.

16. Wilson DO, Sanders MH, Dauber JH. Abnormal ventilatory chemosensitivity and congenital myopathy. Arch Intern Med 1987;147(10): 1773-1777.

17. Kleyweg RP, van der Meche FG, Schmitz PI. Interobserver agreement in the assessment of muscle strength and functional abilities in Guillain-Barré syndrome. Muscle Nerve 1991;14(11):1103-1109.

18. Boles JM, Bion J, Connors A et al. Weaning from mechanical ventilation. Eur Respir J 2007;29(5):1033-1056.

19. Marini JJ, Smith TC, Lamb V. Estimation of inspiratory muscle strength in mechanically ventilated patients: the measurement of maximal inspiratory pressure. J Crit Care 1986;1(1):32-38. 


\section{Central Respiratory Drive in Patients With Neuromuscular Diseases}

20. Sidney DA, Poon CS. Ventilatory responses to dead space and $\mathrm{CO}_{2}$ breathing under inspiratory resistive load. J Appl Physiol 1995;78(2): 555-561.

21. Ranieri VM, Giuliani R, Mascia L, Grasso S, Patruzzelli V, Puntillo $\mathrm{N}$, et al. Patient-ventilator interaction during acute hypercapnia: pressure-support vs proportional-assist ventilation. J Appl Physiol 1996; 81(8):426-436.

22. Raurich JM, Rialp G, Ibañez J, Campillo C, Ayestaran I, Blanco C. Hypercapnia test as a predictor of success in spontaneous breathing trials and extubation. Respir Care 2008;53(8):1012-1018.

23. Kuhlen R, Hausmann S, Pappert D, Slama K, Rossaint R, Falke K. A new method for $\mathrm{P}_{0.1}$ measurement using standard respiratory equipment. Intensive Care Med 1995;21(7):554-560.

24. Subirana M, Irrazabal C, Bak E, Jara F, Mancebo J. Evaluación de la medida de la presión de oclusión incorporada en los ventiladores Evita. Med Intensiva 1997;21(8):305-310. Article in Spanish.

25. Fernandez R, Raurich JM, Mut T, Blanco J, Santos A, Villagra A. Extubation failure: diagnostic value of occlusion pressure $\left(\mathrm{P}_{0.1}\right)$ and $\mathrm{P}_{0.1}$-derived parameters. Intensive Care Med 2004;30(2):234240.

26. Raurich JM, Rialp G, Ibanez J, Llompart-Pou JA, Ayestaran I. $\mathrm{CO}_{2}$ response and duration of weaning from mechanical ventilation. Respir Care 2011;56(8):1130-1136.

27. Altose MD, McCauley WC, Kelsen SG, Cherniack NS. Effects of hypercapnia and inspiratory flow-resistive loading on respiratory activity in chronic airways obstruction. J Clin Invest 1977;59(3): 500-507.

28. Tantucci C, Bottini P, Fiorani C, Dottorini ML, Santeusanio F, Provinciali $\mathrm{L}$, et al. Cerebrovascular reactivity and hypercapnic respi- ratory drive in diabetic autonomic neuropathy. J Appl Physiol 2001; 90(3):889-896

29. Low PA, Engstrom JW. Disorders of the autonomic nervous system. In: Fauci AS, Braunwald E, Kasper DL, Hauser SL, Longo DL, Jameson JL, et al, editors. Harrison's principles of internal medicine, 17th edition. New York: McGraw-Hill; 2008:2576-2582.

30. Schmidt H, Müller-Werdan U, Nuding S, Hoffmann T, Francis DP, Hoyer D, et al. Impaired chemoreflex sensitivity in adult patients with multiple organ dysfunction syndrome: the potential role of disease severity. Intensive Care Med 2004;30(4):665-672.

31. Mazzeo AT, La ME, Di LR, Vita G, Santamaria LB. Heart rate variability: a diagnostic and prognostic tool in anesthesia and intensive care. Acta Anaesthesiol Scand 2011;55(7):797-811.

32. Dhand UK. Clinical approach to the weak patient in the intensive care unit. Respir Care 2006;51(9):1024-1040.

33. Sundar U, Abraham E, Gharat A, Yeolekar ME, Trivedi T, Dwivedi N. Neuromuscular respiratory failure in Guillain-Barré Syndrome: evaluation of clinical and electrodiagnostic predictors. J Assoc Physicians India 2005;53:764-768.

34. Nguyen TN, Badjatia N, Malhotra A, Gibbons FK, Qureshi MM, Greenberg SA. Factors predicting extubation success in patients with Guillain-Barré syndrome. Neurocrit Care 2006;5(3):230-234.

35. Fourrier F, Robriquet L, Hurtevent JF, Spagnolo S. A simple functional marker to predict the need for prolonged mechanical ventilation in patients with Guillain-Barré syndrome. Crit Care 2011;15(1): R65.

36. Sassoon CSH, Te TT, Mahutte CK, Light RW. Airway occlusion pressure. An important indicator for successful weaning in patients with chronic obstructive pulmonary disease. Am Rev Respir Dis 1987;135(1):107-113.

This article is approved for Continuing Respiratory Care Education credit. For information and to obtain your CRCE

(free to AARC members) visit

www.rcjournal.com 